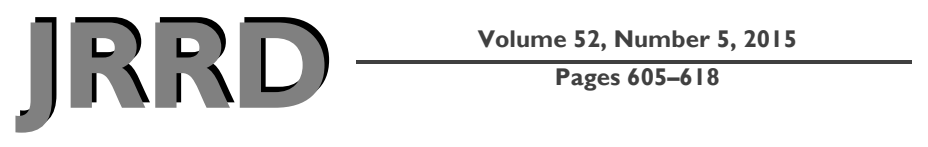

\title{
Impact of Michelangelo prosthetic hand: Findings from a crossover longitudinal study
}

\author{
Martina Luchetti; ${ }^{1 *}$ Andrea G. Cutti, PhD ${ }^{2}$ Gennaro Verni ${ }^{2}{ }^{2}$ Rinaldo Sacchetti; ${ }^{2}$ Nicolino Rossi, MD ${ }^{1}$ \\ ${ }^{1}$ Department of Psychology, University of Bologna, Bologna, Italy; ${ }^{2}$ Centro Protesi INAIL (INAIL Prosthesis Center), \\ Bologna, Italy
}

\begin{abstract}
This work explores the functional and psychosocial impact of the multigrip Michelangelo (M) prosthetic hand. Transradial myoelectric prosthesis users (6 men, median age: 47 y) participated in a crossover longitudinal study. A multifactorial assessment protocol was applied before the application of $\mathrm{M}$ and after $3 \mathrm{mo}$ (functional assessment) and 6 mo (psychosocial assessment) of home use. Functional assessment included both practical tests (i.e., Southampton Hand Assessment Procedure [SHAP], Box and Blocks Test [BBT], and Minnesota Manual Dexterity Test [MMDT]) and self-report functional scales. Psychosocial assessment consisted of a clinical interview and a battery of self-report questionnaires concerning current anxious-depressive symptoms and healthrelated quality of life, body image concerns, adjustment and satisfaction with prosthesis, social support, coping style, and personality. Increased manual dexterity was observed after 3 mo based on improvements in the SHAP, BBT, and MMDT. Two important themes emerged from the clinical interviews at the 6 mo follow-up: (1) the enhanced functionality and (2) the "like a real hand" aspect of the M, which further increased prosthesis integration to the Self. A few patients expressed concerns about $\mathrm{M}$ dimension, noise, and weight. The $\mathrm{M}$ appeared to restore hand function and natural appearance. The present findings provide preliminary evidence, and additional studies are needed.
\end{abstract}

Key words: amputation, crossover study, functional assessment, longitudinal design, manual dexterity, multidisciplinary approach, prosthesis, psychosocial assessment, technology assessment, upper limb.

\section{INTRODUCTION}

Over the past $8 \mathrm{yr}$, new myoelectrically controlled, multi-articulated hands have become available that allow human-like movements and improved grasping capabilities compared with traditional tridigital (TD) myoelectric devices [1-2]. As such, they can potentially address both functional [3] and cosmetic [4] user needs and have positive psychosocial implications [5-9]. However, the actual impact of these technologies on patients' lives has been documented in only two case reports [10-11]. The question

\footnotetext{
Abbreviations: $\mathrm{ABIS}=$ Amputee Body Image Scale; $\mathrm{ADL}=$ activity of daily living; $\mathrm{BBT}=$ Box and Blocks Test; CISS = Coping Inventory for Stressful Situations; DASH = Disabilities of the Arm, Shoulder, and Hand; EPQR-SF = Eysenck Personality Questionnaire Revisited-Short Form; HADS = Hospital Anxiety and Depression Scale; IPA = Interpretative Phenomenological Analysis; $\mathrm{M}=$ Michelangelo; $\mathrm{MDC}_{90}=$ minimum detectable change; MMDT $=$ Minnesota Manual Dexterity Test; MSPSS $=$ Multidimensional Scale Perceived Social Support; OPUS-UEFS = Orthotics and Prosthetics User Survey-Upper Extremity Functional Status module; SHAP = Southampton Hand Assessment Procedure; T0 = baseline; T1 = 3 mo follow-up; T2 $=6$ mo follow-up; TAPES $=$ Trinity Amputation and Prosthesis Experience Scales; TD $=$ tridigital.

*Address all correspondence to Martina Luchetti, Department of Psychology, University of Bologna, Viale Berti Pichat 5, 40127 Bologna, Italy; +39-328-9768028.

Email: luchetti.martina@libero.it http://dx.doi.org/10.1682/JRRD.2014.11.0283
} 
remains whether advanced devices may be more suited for some people with amputation and less for others based on underlying patient characteristics [12-15].

The aim of the present study is to provide preliminary evidence of the potential benefits of the new "handwrist system" Michelangelo (M) (Ottobock Healthcare Products GmbH; Vienna, Austria) in comparison with traditional myoelectric solutions in a sample of participants with transradial amputation. Both functional and psychosocial outcomes were assessed [16]. Specifically, we hypothesized increased manual dexterity and easier execution of activities of daily living (ADLs) along with improvements in social interactions and greater prosthesis satisfaction.

\section{METHODS}

\section{Participants}

Six participants with upper-limb amputation referred to the same prosthetic center of the Italian Workers' Compensation Authority (INAIL Prosthetic Center, Vigorso di Budrio, Bologna, Italy) participated in this study. All participants were male, had a work-related traumatic amputation at the transradial level, and met the inclusion criteria reported in Table 1 (pseudonyms were used to protect subject identities). Participant median age was $47 \mathrm{yr}$ (range: $35-65 \mathrm{yr}$ ), and the median time since amputation was $15 \mathrm{yr}$ (range: $4.5-48.0 \mathrm{yr}$ ). Most participants had a high school education $(83.3 \%)$ and were married or lived with a partner $(66.7 \%)$. Three reported phantom limb sensation and pain experiences that did not, however, affect prosthesis use. All participants used their prosthesis for $>8 \mathrm{~h} / \mathrm{d}$.

\section{Prosthetic Device}

The $M$ is a multi-articulated hand-wrist system. It uses standard myoelectric control, typically through two electrodes that capture the contraction of the forearm muscles. Because of the particular finger alignment and the motorized thumb, the $\mathrm{M}$ can perform seven grasping patterns and hand positions (Figure 1). With the thumb in opposition, the $\mathrm{M}$ can realize an opposition power grip and a tripod pinch with the index and middle fingers. When the thumb moves into abduction, the $\mathrm{M}$ can realize a lateral power grip and a lateral pinch with respect to the index finger. The fingers can be fully extended to reach an open palm position (e.g., for holding a plate). In addition, during opening and closing, fingers move into abduction-adduction; this feature can be exploited to hold flat objects, e.g., grasping a paper or collecting multiple glasses at once. The hand can also assume a neutral position similar to the attitude of the hand when relaxed alongside the body; the hand returns automatically to this position when inactive for a fixed amount of time.

The $M$ is a hand-wrist system because the hand is proximally connected to a passive joint replicating wrist flexion-extension and pronation-supination; the wrist flexion-extension can be either locked in eight different angles or be used in the full range of motion against the resistance of a spring that resets the wrist to the neutral position.

\section{Table 1.}

Characteristics of selected sample. Inclusion criteria include aged 18 to $65 \mathrm{yr}$ (active workers), active prosthetic user (based on usual wear of gloves returned to INAIL Prosthetic Center), work-related unilateral transradial amputation with preserved function of contralateral limb, stabilized residual limb, presence of at least one usable electromyography signal, ability to suspend work activity for period of occupational therapy and testing, and ability to travel to and stay at INAIL Prosthetic Center.

\begin{tabular}{lccccll}
\hline \multicolumn{1}{c}{ Pseudonym } & Age (yr) & $\begin{array}{c}\text { Amputation } \\
\text { Side }\end{array}$ & $\begin{array}{c}\text { Dominant } \\
\text { Hand }\end{array}$ & $\begin{array}{c}\text { Time Since } \\
\text { Amputation (yr) }\end{array}$ & Employment & Marital Status \\
\hline Stefano & 42 & $\mathrm{R}$ & $\mathrm{R}$ & 4 & Unemployed & $\begin{array}{l}\text { Lives with } \\
\text { Partner }\end{array}$ \\
Fabio & 53 & $\mathrm{R}$ & $\mathrm{R}$ & 35 & Office Worker & Divorced \\
Guido & 35 & $\mathrm{R}$ & $\mathrm{R}$ & 10 & Unemployed & Single \\
Francesco & 65 & $\mathrm{~L}$ & $\mathrm{R}$ & 48 & Retired & Married \\
Paolo & 43 & $\mathrm{~L}$ & $\mathrm{R}$ & 20 & Businessman & Married \\
Alberto & 51 & $\mathrm{~L}$ & $\mathrm{R}$ & 8 & Office Worker & Married \\
\hline $\mathrm{L}=$ left, $\mathrm{R}=$ right. & & & & & \\
\hline \hline
\end{tabular}




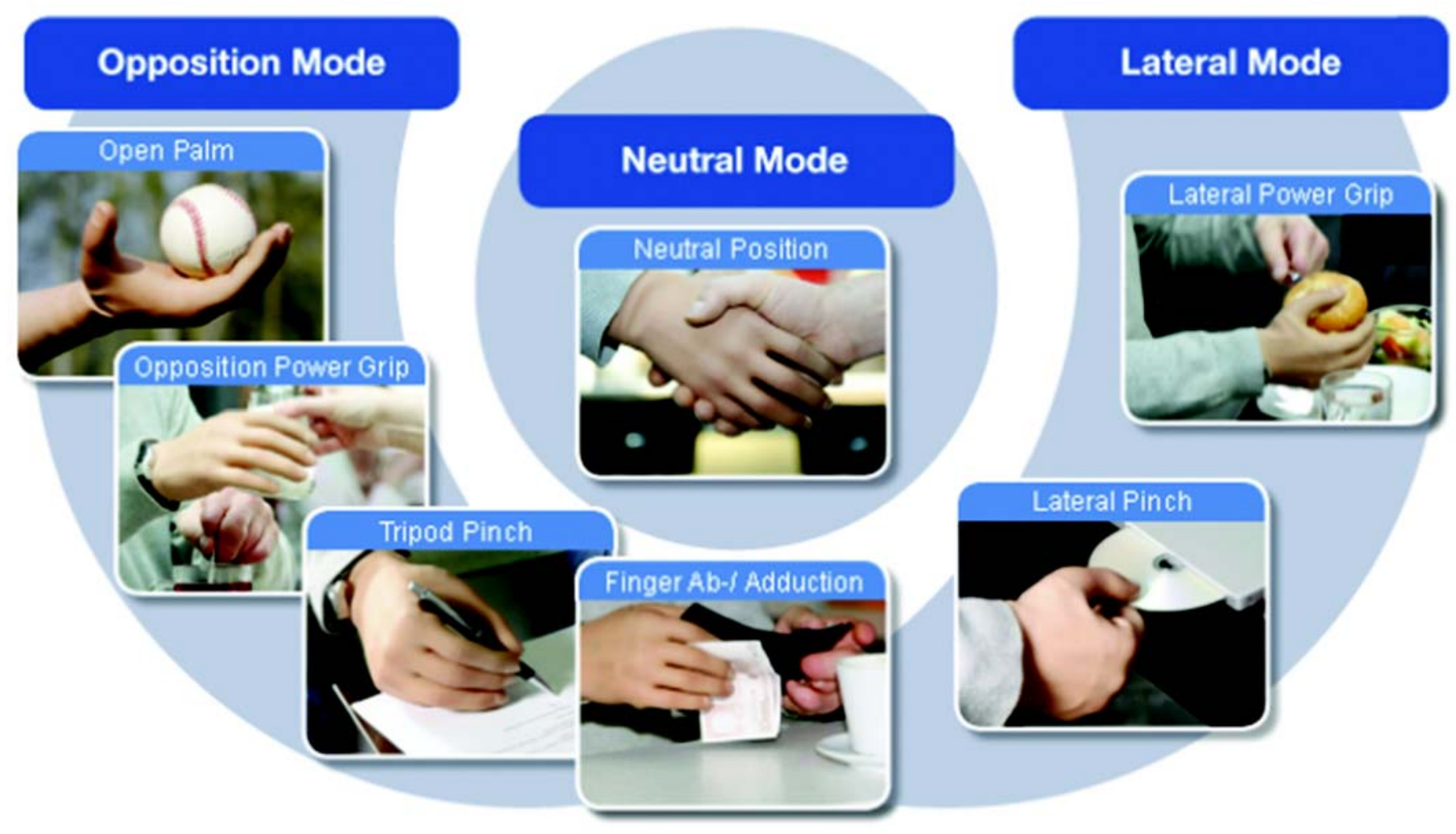

Figure 1.

Gripping patterns of Michelangelo prosthetic hand. This image was previously published in Cutti et al. [11] and is used with permission from Ottobock Healthcare Products GmbH (Vienna, Austria).

The first commercial version of the M (2013) was fitted to all patients.

\section{Study Design and Procedure}

A multifactorial assessment protocol was applied to assess the functional and psychosocial effect of the $M$ (Figure 2). The functional assessment consisted of a series of practical tests and self-report functional scales; practical tests were performed with the standard TD myoeletric hand (Ottobock Healthcare Products $\mathrm{GmbH}$ ) of each patient, the intact hand, and the M. The psychosocial assessment consisted of a clinical interview and a battery of self-report questionnaires.

As illustrated in Figure 2, data were collected before $\mathrm{M}$ fitting to establish a baseline (T0). After provision of the new system and completion of the specific $5 \mathrm{~d}$ of occupational therapy, patients performed functional assessments at the 3 mo follow-up (T1) and psychosocial assessments at the 6 mo follow-up (T2). Since the study protocol was time-consuming and potentially tiring for the participants, the different distribution of functional and psychological assessments allowed for reducing the related burden. To monitor the use of $\mathrm{M}$ in daily life, the number of opening and closing cycles at $\mathrm{T} 1$ and $\mathrm{T} 2$ for the lateral and opposition grip was extracted from the system's internal memory.

Data collection was approved by the Institutional Review Board of INAIL Prosthesis Center. Informed written consent was obtained at the beginning of the study and reviewed verbally before each assessment.

\section{Prosthesis Preparation and Occupational Therapy}

For each patient, a new prosthesis was built due to incompatibility of the new Axon-Bus Prosthetic System (Ottobock Healthcare Products $\mathrm{GmbH}$ ) with the standard quick disconnect. However, the socket was a copy of the one used for the TD, incorporating the same type of electrodes (13E200, Ottobock Healthcare Products GmbH). The M control system (Axon Master, Ottobock Healthcare Products $\mathrm{GmbH}$ ) was customized for each subject 
M Home Use

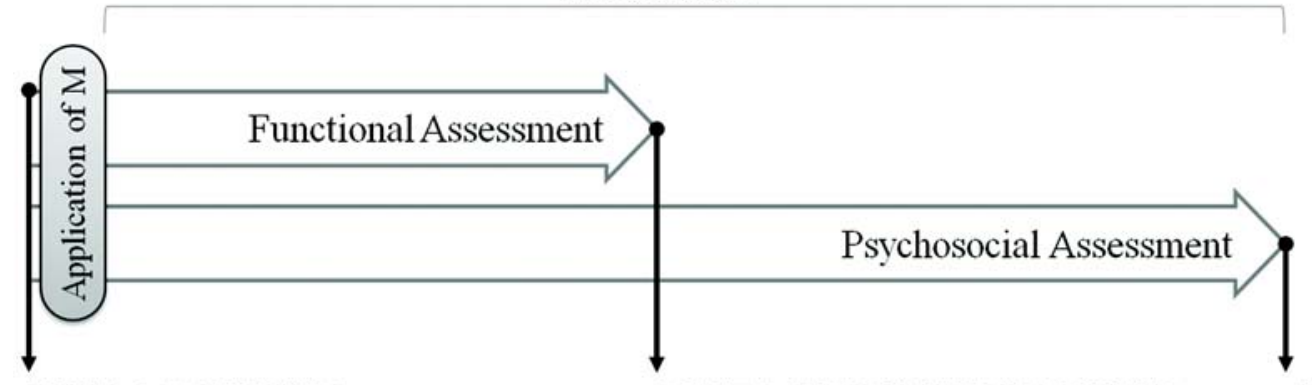

TIME 0 (BASELINE)

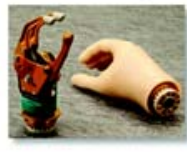

Functional Assessment:

$\mathrm{BBT}+\mathrm{MMDT}+\mathrm{SHAP}+\mathrm{DASH}$

Psychosocial Assessment:

Interview + HADS + EQ-5D + ABIS

+ TAPES + MSPSS + CISS + EPQR-SF
TIME 1 (3-MONTH FOLLOW-UP)

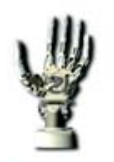

Functional Assessment:

$\mathrm{BBT}+\mathrm{MMDT}+\mathrm{SHAP}+\mathrm{DASH}$

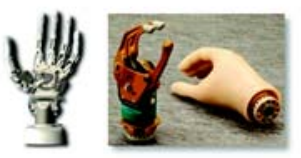

Functional Assessment:

OPUS
TIME 2 (6-MONTH FOLLOW-UP)

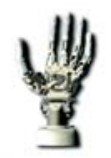

Psychosocial Assessment:

Interview + HADS + EQ-5D + ABIS + TAPES

Figure 2.

Study design. Portions of this image were previously published in Cutti et al. [11] and are used with permission from Ottobock Healthcare Products GmbH (Vienna, Austria). ABIS = Amputee Body Image Scale; BBT = Box and Blocks Test; CISS = Coping Inventory for Stressful Situations; DASH = Disabilities of the Arm, Shoulder, and Hand; EPQR-SF = Eysenck Personality Questionnaire RevisitedShort Form; EQ-5D = EuroQoL Questionnaire; HADS = Hospital Anxiety Depression Scale; $M$ = Michelangelo prosthetic hand; MMDT = Minnesota Manual Dexterity Test; MSPSS = Multidimensional Scale Perceived Social Support; OPUS = Orthotics and Prosthetics User Survey; SHAP = Southampton Hand Assessment Procedure; TAPES = Trinity Amputation and Prosthesis Experience Scales.

with adjustments at time of fitting and during the occupational therapy. Cocontraction was set as the switching strategy between grips, with lateral set as default at device switch-on.

Occupational therapy was performed on a daily basis for about $4 \mathrm{~h} / \mathrm{d}$ for $5 \mathrm{~d}$ and consisted of three main phases:

1. Base control: Training on hand opening, closing, and switching between grips with the arm in different positions in space. Special attention was paid to the lateral and neutral modes. Moreover, we verified patients' ability to successfully switch between grips with a success rate of at least 90 percent.

2. Repetitive drills: Simple manipulation tasks with objects of different weights and sizes in different positions and heights relative to the patient. Special attention was paid in exploiting the flexible wrist (Appendix 1, available online only).
3. ADLs: Execution of ADLs of interest to the participants with special attention paid to bimanual activities and exploitation of $\mathrm{M}$ grips (Appendixes $\mathbf{2}$ and 3, available online only).

\section{Measures}

\section{Functional Assessment}

Practical tests were completed at both T0 and T1. Specifically, participants completed the Southampton Hand Assessment Procedure (SHAP) [17], Box and Blocks Test (BBT) [18], and Minnesota Manual Dexterity Test (MMDT) [19] with both the prosthetic and intact hands (Table 2). The SHAP was assumed to be the primary hand functionality outcome.

Patients also completed the Disabilities of the Arm, Shoulder, and Hand (DASH) [20] at T0 and T1. The 
Table 2.

Description of outcome measures.

\begin{tabular}{|c|c|c|c|c|}
\hline Measure & Measure & $\begin{array}{l}\text { Materials, Task, } \\
\text { and Description }\end{array}$ & Score & Interpretation \\
\hline \multicolumn{5}{|c|}{ Functional Assessment } \\
\hline $\begin{array}{l}\text { UL Physical } \\
\text { Function in ADL }\end{array}$ & OPUS-UEFS & $\begin{array}{l}\text { Participants completed } 23 \text {-item } \\
\text { self-report questionnaire with } 5 \text { - } \\
\text { point response scale that mea- } \\
\text { sures ease of execution of } \\
\text { ADLs. }\end{array}$ & $\begin{array}{l}\text { From } 0 \text { to } 100 \text { (Resnick } \\
\text { and Borgia method), per- } \\
\text { centage of ADLs per- } \\
\text { formed with prosthesis. }\end{array}$ & $\begin{array}{l}\text { Higher score = lower } \\
\text { functionality. }\end{array}$ \\
\hline $\begin{array}{l}\text { Health-Related } \\
\text { QoL }\end{array}$ & $\begin{array}{l}\text { EuroQoL } \\
\text { Questionnaire }\end{array}$ & $\begin{array}{l}\text { Participants completed } 5 \text { items } \\
\text { (mobility, self-care, usual activ- } \\
\text { ities, pain and discomfort, and } \\
\text { anxiety and depression) with 3- } \\
\text { point response scale (IDX); } \\
\text { VAS to rate perceived health } \\
\text { status. }\end{array}$ & $\begin{array}{l}\text { IDX }=0-1 ; \text { VAS }=0- \\
100 .\end{array}$ & $\begin{array}{l}\text { Higher score = higher } \\
\text { QoL. }\end{array}$ \\
\hline $\begin{array}{l}\text { Body Image } \\
\text { Concerns }\end{array}$ & ABIS & $\begin{array}{l}\text { Participants completed } 20 \text {-item } \\
\text { self-report questionnaire with } 5 \text { - } \\
\text { point response scale specifically } \\
\text { developed to investigate body } \\
\text { image concerns in persons with } \\
\text { amputation. }\end{array}$ & $\begin{array}{l}\text { From } 20 \text { to } 100 \text { (raw } \\
\text { score }[\text { sum]). }\end{array}$ & $\begin{array}{l}\text { Higher score = more } \\
\text { concerns. }\end{array}$ \\
\hline
\end{tabular}


JRRD, Volume 52, Number 5, 2015

Table 2. (cont)

Description of outcome measures.

\begin{tabular}{|c|c|c|c|c|}
\hline Measure & Measure & $\begin{array}{l}\text { Materials, Task, } \\
\text { and Description }\end{array}$ & Score & Interpretation \\
\hline $\begin{array}{l}\text { Adjustment to } \\
\text { Prosthesis }\end{array}$ & TAPES & $\begin{array}{l}\text { Participants completed multidi- } \\
\text { mensional self-report measure } \\
\text { specifically developed to inves- } \\
\text { tigate postamputation adjust- } \\
\text { ment: } 4 \text { psychosocial scales } \\
\text { (TAPES1), } 4 \text { activity-restric- } \\
\text { tion scales (TAPES2), and } 1\end{array}$ & $\begin{array}{l}\text { TAPES1: General Adjust- } \\
\text { ment }=3-15, \text { Social } \\
\text { Adjustment }=4-20, \\
\text { Adjustment to Limitation= } \\
\text { 5-25, Optimal Adjust- } \\
\text { ment }=2-10 \text {; TAPES2: } \\
\text { Athletic Activity Restric- }\end{array}$ & $\begin{array}{l}\text { TAPES1: higher score }= \\
\text { higher psychosocial } \\
\text { adjustment; TAPES2: } \\
\text { lower score = lower activ- } \\
\text { ity restriction; TAPES3: } \\
\text { higher score = higher } \\
\text { prosthesis satisfaction. }\end{array}$ \\
\hline
\end{tabular}

prosthesis satisfaction scale (TAPES3).

\begin{tabular}{|c|c|c|c|}
\hline $\begin{array}{l}\text { Perceived Social } \\
\text { Support }\end{array}$ & MSPSS & $\begin{array}{l}\text { Participants completed } 12 \text {-item } \\
\text { self-report questionnaire with } 7 \text { - } \\
\text { point response scale with } 3 \\
\text { scales: family, friends, and sig- } \\
\text { nificant other. }\end{array}$ & $\begin{array}{l}\text { From } 4 \text { to } 28 \text { for each } \\
\text { scale (score [sum]). }\end{array}$ \\
\hline Coping & CISS & $\begin{array}{l}\text { Participants completed } 48 \text {-item } \\
\text { self-report questionnaire with 5- } \\
\text { point response scale with } 3 \\
\text { scales: task, emotion, and } \\
\text { avoidance-oriented coping. }\end{array}$ & $\begin{array}{l}\text { Raw scores (sum) trans- } \\
\text { formed into T scores } \\
\text { (mean of general popula- } \\
\text { tion }=50) \text {. }\end{array}$ \\
\hline Personality & EPQR-SF & $\begin{array}{l}\text { Participants completed 48-item } \\
\text { self-report questionnaire with } \\
\text { dichotomy answer that mea- } \\
\text { sures } 3 \text { dimensions of personal- } \\
\text { ity (Psychoticism, Extraversion, } \\
\text { and Neuroticism [with Lie } \\
\text { scale]). }\end{array}$ & $\begin{array}{l}\text { Raw scores (sum) trans- } \\
\text { formed into T scores } \\
\text { (mean of general popula- } \\
\text { tion }=50) \text {. }\end{array}$ \\
\hline
\end{tabular}

$$
\text { tion }=0-6 \text {, Social }
$$

Restriction $=0-4$, Occupational Restriction $=0$ 4, Mobility Restriction $=$ 0-10; TAPES3: 10-50

(raw score [sum]).

Higher score $=$ higher perceived support.

Higher score $=$ higher levels of coping ability.

Higher score $=$ higher levels of personality dimension.

ABIS = Amputee Body Image Scale; ADL = activity of daily living; BBT = Box and Blocks Test; CISS = Coping Inventory for Stressful Situations; DASH = Disabilities of the Arm, Shoulder, and Hand; EPQR-SF = Eysenck Personality Questionnaire Revisited-Short Form; HADS = Hospital Anxiety Depression Scale; IDX = summary index; IoF = Index of Functionality; MMDT = Minnesota Manual Dexterity Test; MSPSS = Multidimensional Scale Perceived Social Support; OPUSUEFS = Orthotics and Prosthetics User Survey-Upper Extremity Functional Status module; QoL = quality of life; SHAP = Southampton Hand Assessment Procedure; TAPES = Trinity Amputation and Prosthesis Experience Scales; UL = upper limb; VAS = visual analog scale.

Orthotics and Prosthetics User Survey-Upper Extremity Functional Status module (OPUS-UEFS) [21] was administered only at $\mathrm{T} 1$ and asks participants to separately complete the same form about the TD and $\mathrm{M}$; the sequence was balanced within the sample. In the present study, we used the Resnick and Borgia scoring method, calculating person-level summary scores [22].

\section{Psychosocial Assessment}

A clinical interview was conducted and a battery of self-report questionnaires was administered both at T0 and T2. All interviews were audiotaped and transcribed verbatim. The ideographic case study approach of the Interpretative Phenomenological Analysis (IPA) was applied for a qualitative analysis of the content [23]. Even if preordained lists of questions are not typically adopted for IPA case studies, an interview schedule was defined in order to cover the main aspects of the participants' amputation and prosthesis experiences. The schedule was used as a flexible guide but did not restrict the direction of discussions or resultant themes. The interviewer was a clinical psychologist with no visible disabilities. 
The duration of the interviews varied but generally lasted about $50 \mathrm{~min}$.

The battery of questionnaires assessed different aspects of the participants' psychological functioning, such as current anxious-depressive symptoms (i.e., Hospital Anxiety and Depression Scale [HADS]) [24-25], health-related quality of life (i.e., EuroQoL Questionnaire, 5 Dimensions) [26], perceived social support (i.e., Multidimensional Scale Perceived Social Support [MSPSS]) [27-28], coping styles (Coping Inventory for Stressful Situations [CISS]) [29], and personality characteristics (Eysenck Personality Questionnaire RevisitedShort Form [EPQR-SF]) [30]. For a detailed description of administered questionnaires, refer to Table 2.

Moreover, participants completed the Amputee Body Image Scale (ABIS) [31-32] and the Trinity Amputation and Prosthesis Experience Scales (TAPES)-Upper Limb Version [33-35] to investigate body image concerns and adjustment to the prosthesis (Table 2). Although designed for people with lower-limb amputation, these scales have also been applied on samples of people with upper-limb amputation [8,34]. Italian versions were obtained through the back-translation method. Some of the ABIS items that refer to the lower limb were rephrased for upper-limb amputation, e.g., "I avoid wearing shorts in public because my prosthesis would be seen" became "I avoid wearing T-shirts [. . .]."

Lastly, note that the MSPSS, CISS, and EPQR-SF were only administered at $\mathrm{T} 0$ because they address stable variables (i.e., perceived social support, coping, and personality characteristics).

\section{RESULTS}

Four out of six participants experienced at least one temporary device failure of $\mathrm{M}$ over the study period. $\mathrm{T} 1$ (i.e., functional assessment) was completed, on median, after 99 d (range: 94-101 d) of effective home use; T2 was accomplished after $200 \mathrm{~d}$ (range: 181-225 d).

\section{Monitoring of Michelangelo Home Use}

At T1, activity monitoring data downloaded from the $M$ showed that the median number of opening and closing cycles was 32,330 (range: 20,143-42,844), with one noticeable exception represented by subject Guido, who reached 218,948 cycles. Five out of six patients showed a clear preference toward the lateral grip for more than 73 percent of cycles (Table 3).

At T2, the median number of cycles reached 54,012 (range: 38,705-83,479), with a peak for subject Guido of 435,208 cycles. The ratio of lateral to opposition grips slightly increased to 77 percent (Table 3).

Projections to a full $1 \mathrm{yr}$ of use without failures, based on a linear model, shows that the minimum number of cycles would be 75,000 with a median of 130,000 and a maximum of 790,000 .

\section{Functional Assessment}

Figure 3 shows the results for the functional assessment (see Appendix 4, available online only, for numerical values). The Index of Functionality of the SHAP was higher at T1 than at T0 (Wilcoxon test, $p<0.05$ ). Significant improvements were observed in the BBT; four participants increased the number of blocks carried over the partition over the minimum detectable change $\left(\mathrm{MDC}_{90}\right.$ 26.46) [22]. Statistically significant changes resulted for the MMDT; all patients decreased their time in completing the task (Wilcoxon test, $p<0.05$ ). A better performance was obtained with the intact hand compared with both TD and M.

The self-report measures broadly confirmed the high functional capacity of the sample. Patients showed low DASH scores in all assessments, with values always lower than 26 points; differences between assessments remained always smaller than the $\mathrm{MDC}_{90}$ (10.7 points) [22].

With respect to the OPUS-UEFS, an easier execution of ADLs with $\mathrm{M}$ was reported at $\mathrm{T} 2$ by five out of six participants (from -0.48 to -8.86 points). Noticeably, the

Table 3.

Activity monitoring (opening and closing cycles count) at $3 \mathrm{mo}$ (T1) and $6 \mathrm{mo}$ (T2) follow-ups.

\begin{tabular}{|c|c|c|c|c|c|c|c|c|c|c|c|c|}
\hline \multirow{2}{*}{$\begin{array}{c}\text { Activity } \\
\text { Monitoring }\end{array}$} & \multicolumn{2}{|c|}{ Stefano } & \multicolumn{2}{|c|}{ Fabio } & \multicolumn{2}{|c|}{ Guido } & \multicolumn{2}{|c|}{ Francesco } & \multicolumn{2}{|c|}{ Paolo } & \multicolumn{2}{|c|}{ Alberto } \\
\hline & T1 & T2 & T1 & $\mathrm{T} 2$ & T1 & $\mathrm{T} 2$ & T1 & $\mathrm{T} 2$ & T1 & T2 & T1 & $\mathrm{T} 2$ \\
\hline $\begin{array}{l}\text { No. of Lateral } \\
\text { Cycles }\end{array}$ & 15,429 & 32,607 & 22,553 & 42,905 & 130,212 & 275,952 & 32,295 & 44,846 & 31,670 & 59,408 & 8,066 & 10,172 \\
\hline Lateral (\%) & 77 & 84 & 70 & 77 & 59 & 63 & 86 & 86 & 74 & 71 & 27 & 26 \\
\hline
\end{tabular}


only patient with an increase in perceived difficulty with M (Fabio) was the one who more intensively complained about the reliability of the M. On the contrary, the patient with the largest improvement (Paolo) never experienced any failure and showed a high count of opening and closing cycles $(42,844$ at $\mathrm{T} 1)$. On average, the participants used the TD and $\mathrm{M}$ for more than 80 percent of the listed activities. Again, Paolo reported the greatest change in the number of activities completed with the M (11 additional activities).

\section{Psychosocial Assessment}

The qualitative analysis of the interviews allowed identifying recurrent themes across assessment time points. Extracts of transcripts (examples) are reported in Appendix 5 (available online only); the scores of the self-report questionnaires are reported in Table 4 and Appendix 6 (available online only).

Specifically, at T0 the following themes and related subthemes emerged:

1. Amputation as a change of life.

2. Factors facilitating adjustment.

a. Beginning to use the prosthesis.

b. Support by others.

3. Having an artificial limb.

a. How does a prosthesis have to be?

b. The prosthesis is essential.

Regarding themes 1 and 2, participants perceived their amputation as a change of life. Despite the initial effect (e.g., relevant anxious-depressive symptoms), they seemed to have successfully overcome the amputation- (a)

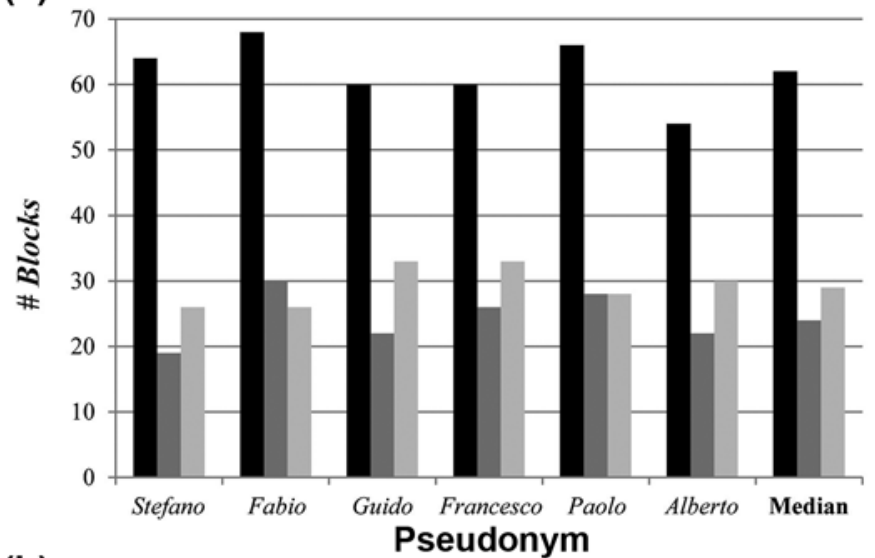

(b)

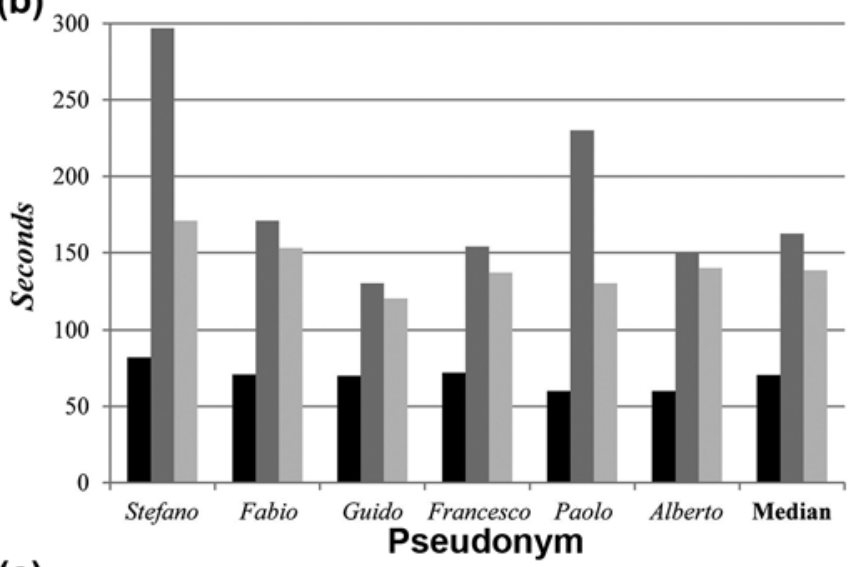

(c)

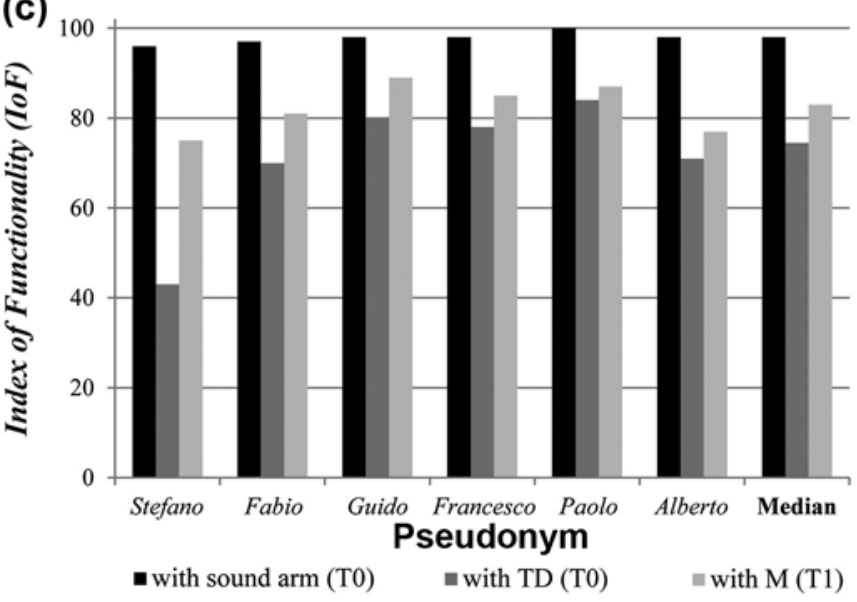

Figure 3.

Results of functional tests. Three diagrams report results for functional tests for each subject and median values of group: (a) Box and Blocks Test (BBT), (b) Minnesota Manual Dexterity Test (MMDT), and (c) Southampton Hand Assessment Procedure (SHAP). Functional improvement is associated with more blocks (BBT), less seconds (MMDT), and higher Index of Functionality (SHAP). T0 = baseline, $\mathrm{T} 1=3 \mathrm{mo}$ follow-up. $\mathrm{M}=$ Michelangelo prosthetic hand, $\mathrm{TD}=$ tridigital prosthetic hand. 
Table 4.

Patient scores on self-report measures of psychological assessment. Individual patient scores are available in Appendix 6 (available online only).

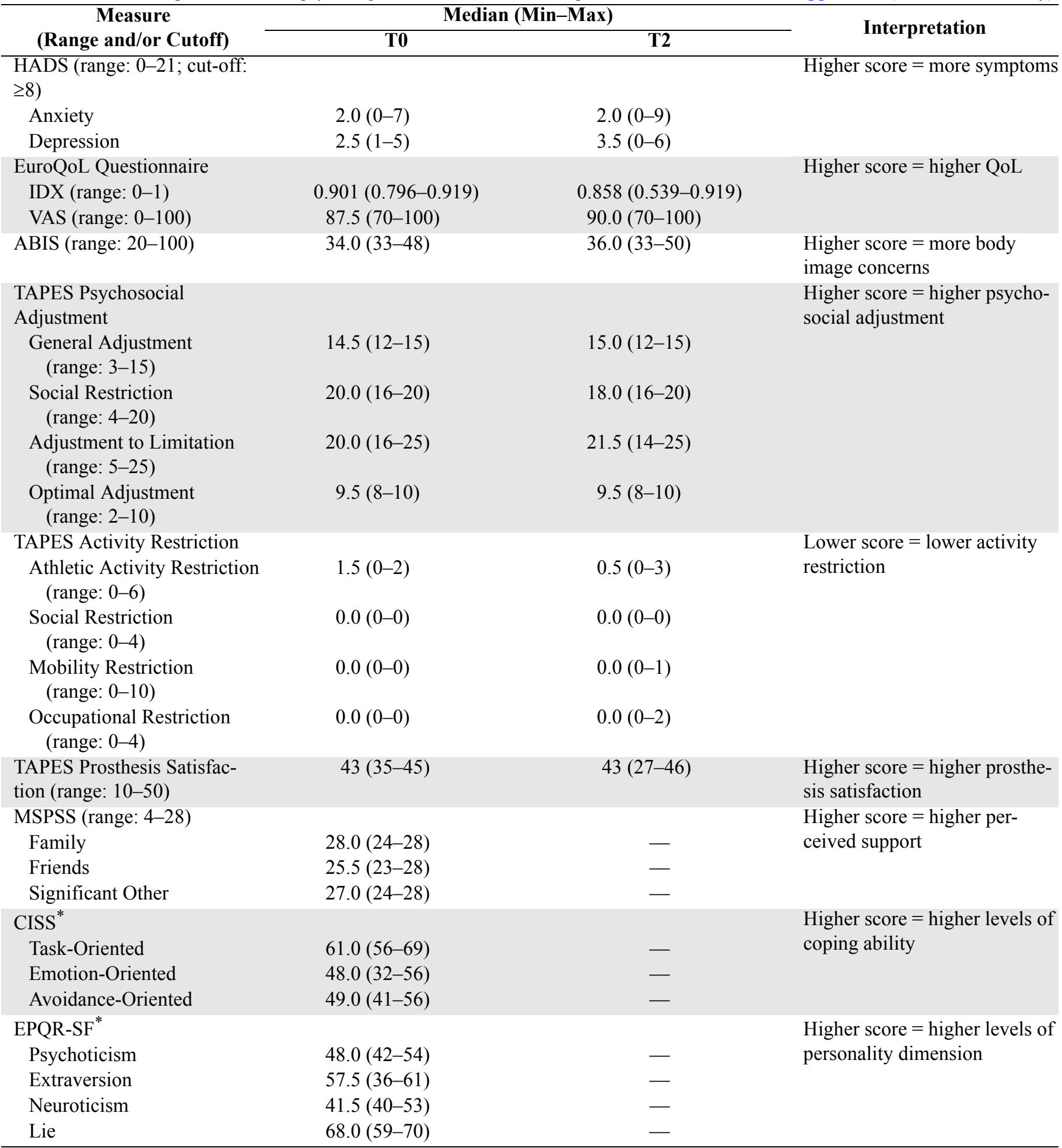

${ }^{*} \mathrm{~T}$ scores are reported $(50=$ mean of general population).

$\mathrm{ABIS}=$ Amputee Body Image Scale, CISS = Coping Inventory for Stressful Situations, EPQR-SF = Eysenck Personality Questionnaire Revisited-Short Form, HADS $=$ Hospital Anxiety Depression Scale, IDX = summary index, Max = maximum, Min $=$ minimum, MSPSS $=$ Multidimensional Scale Perceived Social Support, $\mathrm{QoL}=$ quality of life, $\mathrm{T} 0=$ baseline, $\mathrm{T} 2=6 \mathrm{mo}$ follow-up, TAPES $=$ Trinity Amputation and Prosthesis Experience Scales, VAS = visual analog scale. 
related challenges. A sense of recovery was often reported when describing the beginning of prosthesis use; acceptance and support from family and friends were also identified to be of particular importance in adjusting to the amputation and to overcoming the initial social isolation.

With respect to the prosthesis (theme 3), most of the participants stressed their need for functionality; "It [the prosthesis] has to work" (Guido). However, more profound personal meanings also emerged. For example, the prosthesis allowed for participation in social activities (e.g., playing cards with friends). Importantly, the prosthesis is referred to as "essential"; participants often stated "I do everything with the prosthesis" and "I don't see myself without it." The prosthesis seemed to be experienced not merely as a thing or tool that allows participants to perform ADLs but as a part of the user. Of note, two participants reported a correspondence between phantom limb and prosthesis movements, which "helped" them to use the device.

Self-report questionnaires addressed both stable userrelated variables (i.e., social support, coping, personality) and variables sensitive to intervention (i.e., depression and anxiety, quality of life, prosthesis satisfaction) (Table 4). Regarding the stable variables, participants shared similar psychological characteristics. They reported high levels of social support (high MSPSS scores), especially from family and friends. They also showed a prevalent taskoriented coping style (high CISS task-oriented scale scores), generally adopting practical strategies to face difficulties in life and focusing on concrete aspects of problems. Along with high scores on the CISS taskoriented scale, high scores on the EPQR-SF lie scale were found. These findings, taken together, seem to reflect the pragmatic way in which participants faced their amputation and related to their prosthesis. Indeed, although opened to multiple interpretations, EPQR-SF lie scale scores may reflect not only a mere social acquiescence or conformity but also a sort of lack of insight (individual's tendency to think and behave in concrete terms) [36]. Regarding the variables sensitive to intervention, no relevant anxious-depressive symptoms were observed; HADS scores were below the mostly used cutoff value (i.e., $\geq 8$ ). High levels of health-related quality of life were also reported (visual analog scale scores were generally $>80$ ). No relevant body image concerns were observed (i.e., low ABIS scores); all participants were highly adjusted and satisfied with the TD (i.e., high TAPES scores).

At $\mathrm{T} 2$, although no significant differences were observed in the self-report measures (Wilcoxon tests, $p>$ 0.05 ), interview transcripts showed important changes in the participants' personal experiences with the M. Two main themes were identified:

1. Enhanced functionality in everyday life.

2. Like a real hand-Natural gestures and postures.

a. The $\mathrm{M}$ is less noticeable.

b. The $\mathrm{M}$ helps in social interactions.

In detail, the majority of participants appeared globally satisfied with the M; Appendix 5 (available online only) notes specific issues raised using the $\mathrm{M}$. All participants highlighted the enhanced functionality in performing ADLs. Although they stressed functionality over cosmetics, they seemed to appreciate the natural aspect of the M. In particular, the $\mathrm{M}$ allowed them to assume more natural gestures and postures, reducing the difference from others and facilitating a normal appearance. The social role of the prosthesis became apparent; for example, a participant started to shake hands with the prosthesis. In other words, the $M$ expanded the range of activities relevant to the Self in various contexts (e.g., in performing tasks at work, in interacting with family and friends). The prosthesis seemed to become an integral part of the user: "It completes me." However, unaddressed needs emerged about (1) dimension (Francesco, Alberto), (2) noise (Fabio, Guido, Francesco), and (3) weight (Stefano, Fabio, Alberto). Those who experienced a temporary failure also complained about the reliability of the device (in particular, Fabio and Francesco).

\section{DISCUSSION}

By adopting an original multidisciplinary approach, this crossover longitudinal study provides preliminary evidence on the functional and psychosocial effect of the $\mathrm{M}$, an innovative multigrip myoelectric hand.

Increased manual dexterity was observed after 3 mo of using the $\mathrm{M}$ based on improvements in SHAP, BBT, and MMDT scores. In a sample of highly functional participants (worst case DASH: 26), five out of six subjects improved in the perceived difficulty of ADLs with the M (OPUS-UEFS), with best results in those participants experiencing less failures, possibly because of the increased confidence in the new device. 
Based on the psychosocial assessment, the M seemed to restore hand function and cosmetic appearance. Although no changes were detected in the self-report measures, two main themes emerged from the clinical interviews at T2: (1) the enhanced functionality and (2) the "like a real hand" aspect of the M, which further increases the integration of the prosthesis to the Self. The $\mathrm{M}$ extended the potential of participants, allowing them to fulfill activities relevant for the self. A few participants also identified main elements for further development of the M: dimension, noise, weight, and reliability. Regarding this last aspect, note that the first commercial version of the device was used; given the importance of this feature, a recall of all participants took place 6 mo after the end of the study to verify the condition of the devices. None of them reported further failures. Reliability appears to be a fundamental feature to monitor in the new generation of multifunctional hands.

Aside from the main results, other relevant findings emerged. First, monitoring the actual number of opening and closing cycles confirmed that participants actively used the $\mathrm{M}$ at home, reaching a projected annual use of more than 100,000 cycles. This is, to our knowledge, the first time that the cycle count has been documented for an upper-limb prosthesis during home use over an extended time period. As such, these data can provide useful information for device development and maintenance. The cycle count also provided evidence of the striking preference of participants for the lateral grip, which further increased from $\mathrm{T} 1$ to $\mathrm{T} 2$ to finally reach 77 percent, highlighting the importance of including a lateral grip in the grip types of multifunctional hands. At $\mathrm{T} 1$ and $\mathrm{T} 2$, we verbally asked which was the participant's preferred grip, and five out of six confirmed that it was the lateral (with the exception of Alberto). Even though participants were proficient in grip switching, in a further study it would be interesting to repeat the activity monitoring after imposing opposition as the default grip at prosthesis switch-on. Interestingly, the $\mathrm{M}$ lateral grip is substantially different from that of the iLimb Hand (TouchBionics; Livingston, United Kingdom), because the thumb of the $\mathrm{M}$ closes on the distal part of the index finger and not near the knuckles. Device-specific evaluations are therefore needed for each prosthetic hand.

Second, common psychosocial characteristics were identified among this group of highly functional participants. Based on the clinical interviews and self-report questionnaires, participants showed no relevant anxious- depressive symptoms, exhibited a positive attitude to life, and adopted a practical approach to life-challenging experiences. Moreover, they reported high levels of social support. Task-oriented coping strategies were previously associated with lower levels of anxious-depressive symptoms [5,37], and perceived social support has been found to predict a positive adjustment to amputation [3840]. This study also considers different aspect of personality; although there is insufficient knowledge concerning the traits assessed by the EPQR-SF lie scale [36], the participants' high scores on this scale seem to reflect the practical way in which they coped with limb loss.

Third, as highlighted in previous studies, having a prosthesis appears to reduce the distance between current and former selves and to minimize the perceived difference from others $[9,41]$. In particular, with its normal appearance, the $M$ seemed to facilitate social interactions. For instance, it allowed constituted social manners (i.e., shaking hands with the dominant arm) [42]. Moreover, as functionally useful and cosmetically acceptable, the myoelectric hand seemed to have become part of the user. Thus, embodiment was found to occur [43]; i.e., the prosthesis was viewed not merely as a functional tool but also as an essential part of the Self. The human-like features of the $\mathrm{M}$ the further expanded this embodied form.

While phantom limb pain can severely affect prosthesis control [16], this was not the case for the selected sample based on participant reports. In particular, note that two of the participants, despite the painful sensation, reported that the coincidence of phantom limb movements with prosthesis movements helped them to better control the artificial hand. This confirmed previous findings available in the literature [44].

The current study provides preliminary evidence on the potential functional and psychosocial benefits of the $\mathrm{M}$, considering a group of six participants with amputation, all active users of standard (TD) myoelectric prostheses. Increasing the sample size would be important to strengthen the conclusions and to develop a multifactorial predictive model of successful prosthetic fitting, targeted to multifunctional hands. For this purpose, it will be important to extend the assessment to participants of both sexes and possibly include first-time myoelectric prosthesis users. Last, crossover should be randomized in future studies to control potential confounding variables (e.g., effects of practice in functional tests). 


\section{CONCLUSIONS}

Amputation- and prosthetic-related factors, along with psychological factors (e.g., patient coping strategies, attitude, expectations) and social factors (i.e., support of family and friends, reactions of others), need to be screened in the prosthesis fitting process [45]. The present study shows that the $M$ is effective in improving the functional ability and in easing the social interaction of previous active users of a myoelectric prosthesis.

\section{ACKNOWLEDGMENTS}

\author{
Author Contributions: \\ Study concept and design: M. Luchetti, A. G. Cutti, N. Rossi. \\ Acquisition of data: M. Luchetti, A. G. Cutti. \\ Analysis and interpretation of data: M. Luchetti, A. G. Cutti. \\ Drafting of manuscript: M. Luchetti, A. G. Cutti, G. Verni, \\ R. Sacchetti, N. Rossi. \\ Administrative, technical, or material support: G. Verni.
}

Financial Disclosures: The Department of Psychology, University of Bologna, acknowledges the funding agreement with Ottobock Healthcare Products $\mathrm{GmbH}$ that partially supported this study. Ottobock Healthcare Products $\mathrm{GmbH}$ was not involved in study design, data collection, data analysis, interpretation of results, writing of the article, or decision to submit the article for publication in this journal. Funding/Support: This material was based on work supported by Ottobock Healthcare Products GmbH and the Department of Psychology, University of Bologna.

Additional Contributions: The authors would like to express their gratitude to the INAIL Prosthesis Center staff (Cesare Stagni, Gianni Carrieri, Liseo Lazzari, Roberta Pallotti, and Pericle Randi) for prostheses fitting and occupational therapy training. They also acknowledge the essential contributions of Davide Veronesi, FT, in study design and patient assessment and Dr. Stefania Fatone in completing the back-translations of the ABIS, TAPES, and OPUS-UEFS. Finally, the authors are grateful to John Miguelez CP, FAAOP; Tiffany Ryan OTR, MOT; and Dan Conyers CPO, FAAOP, for the invaluable technical discussions and for their comments on the early versions of the manuscript. Ms. Luchetti is no longer with the University of Bologna. Institutional Review: The study was approved by the Institutional Review Board of INAIL Prosthesis Center. Written consent forms have been collected for all participants.

Participant Follow-Up: The authors plan to inform participants of the publication of this study.

\section{REFERENCES}

1. Belter JT, Segil JL, Dollar AM, Weir RF. Mechanical design and performance specifications of anthropomorphic prosthetic hands: A review. J Rehabil Res Dev. 2013;50(5):
599-618. [PMID:24013909]

http://dx.doi.org/10.1682/JRRD.2011.10.0188

2. Vergara M, Sancho-Bru JL, Gracia-Ibáñez V, PérezGonzález A. An introductory study of common grasps used by adults during performance of activities of daily living. J Hand Ther. 2014;27(3):225-34. [PMID:24878351] http://dx.doi.org/10.1016/j.jht.2014.04.002

3. Datta D, Selvarajah K, Davey N. Functional outcome of patients with proximal upper limb deficiency-acquired and congenital. Clin Rehabil. 2004;18(2):172-77.

[PMID:15053126] http://dx.doi.org/10.1191/0269215504cr716oa

4. Biddiss E, Beaton D, Chau T. Consumer design priorities for upper limb prosthetics. Disabil Rehabil Assist Technol. 2007;2(6):346-57. [PMID:19263565] http://dx.doi.org/10.1080/17483100701714733

5. Desmond DM. Coping, affective distress, and psychosocial adjustment among people with traumatic upper limb amputations. J Psychosom Res. 2007;62(1):15-21.

[PMID:17188116]

http://dx.doi.org/10.1016/j.jpsychores.2006.07.027

6. Østlie K, Magnus P, Skjeldal OH, Garfelt B, Tambs K. Mental health and satisfaction with life among upper limb amputees: A Norwegian population-based survey comparing adult acquired major upper limb amputees with a control group. Disabil Rehabil. 2011;33(17-18):1594-1607. [PMID:21166612] http://dx.doi.org/10.3109/09638288.2010.540293

7. Cheung E, Alvaro R, Colotla VA. Psychological distress in workers with traumatic upper- or lower-limb amputations following industrial injuries. Rehabil Psychol. 2003;48(2): 109-12. http://dx.doi.org/10.1037/0090-5550.48.2.109

8. Desteli EE, İmren Y, Erdoğan M, Sarısoy G, Coşgun S. Comparison of upper limb amputees and lower limb amputees: A psychosocial perspective. Eur J Trauma Emerg Surg. 2014;40:735-39. http://dx.doi.org/10.1007/s00068-014-0418-3

9. Saradjian A, Thompson AR, Datta D. The experience of men using an upper limb prosthesis following amputation: Positive coping and minimizing feeling different. Disabil Rehabil. 2008;30(11):871-83. [PMID:17852212] http://dx.doi.org/10.1080/09638280701427386

10. van der Niet O, Bongers RM, van der Sluis CK. Functionality of i-LIMB and i-LIMB pulse hands: Case report. J Rehabil Res Dev. 2013;50(8):1123-28. [PMID:24458898] http://dx.doi.org/10.1682/JRRD.2012.08.0140

11. Cutti AG, Parel I, Luchetti M, Gruppioni E, Rossi NC, Verni G. The psychosocial and biomechanical assessment of amputees fitted with commercial multi-grip prosthetic hands. In: Parenti Castelli V, Troncossi M, editors. Grasping the future: Advances in powered upper limb prosthet- 
ics. Sharjah (U.A.E.): Bentham Science Publishers; 2012. p. 59-77.

12. Biddiss EA, Chau TT. Multivariate prediction of upper limb prosthesis acceptance or rejection. Disabil Rehabil Assist Technol. 2008;3(4):181-92. [PMID:19238719] http://dx.doi.org/10.1080/17483100701869826

13. Østlie K, Lesjø IM, Franklin RJ, Garfelt B, Skjeldal OH, Magnus P. Prosthesis rejection in acquired major upperlimb amputees: A population-based survey. Disabil Rehabil Assist Technol. 2012;7(4):294-303. [PMID:22112174] http://dx.doi.org/10.3109/17483107.2011.635405

14. Mhurchadha SN, Schaffalitzky E, Gallagher P, MacLachlan M. Psychological fit of a prosthetic arm: An illustrative case study using repertory grid analysis with a user of a high-tech upper limb prosthesis. In: Gallagher P, Desmond D, MacLachlan M, editors. Psychoprosthetics. London (UK): Springer; 2008. p. 155-61.

15. Schaffalitzky E, NiMhurchadha S, Gallagher P, Hofkamp S, MacLachlan M, Wegener ST. Identifying the values and preferences of prosthetic users: A case study series using the repertory grid technique. Prosthet Orthot Int. 2009; 33(2):157-66. [PMID:19367519] http://dx.doi.org/10.1080/03093640902855571

16. Murray CD. Amputation, prostheses, and phantom limb pain: An interdisciplinary perspective. London (UK): Springer-Verlag; 2010.

17. Light CM, Chappell PH, Kyberd PJ. Establishing a standardized clinical assessment tool of pathologic and prosthetic hand function: Normative data, reliability, and validity. Arch Phys Med Rehabil. 2002;83(6):776-83.

[PMID:12048655]

http://dx.doi.org/10.1053/apmr.2002.32737

18. Mathiowetz V, Volland G, Kashman N, Weber K. Adult norms for the Box and Block Test of manual dexterity. Am J Occup Ther. 1985;39(6):386-91. [PMID:3160243] http://dx.doi.org/10.5014/ajot.39.6.386

19. Lafayette Instrument Company. The complete Minnesota Dexterity Test examiner's manual. Lafayette (IN): Lafayette Instrument Company; 1969.

20. Hudak PL, Amadio PC, Bombardier C; The Upper Extremity Collaborative Group (UECG). Development of an upper extremity outcome measure: The DASH (Disabilities of the Arm, Shoulder, and Hand) [corrected]. Am J Ind Med. 1996; 29(6):602-8. [PMID:8773720]

21. Heinemann AW, Bode RK, O'Reilly C. Development and measurement properties of the Orthotics and Prosthetics Users' Survey (OPUS): A comprehensive set of clinical outcome instruments. Prosthet Orthot Int. 2003;27(3):191206. [PMID:14727700] http://dx.doi.org/10.1080/03093640308726682
22. Resnik L, Borgia M. Reliability and validity of outcome measures for upper limb amputation. JPO. 2012;24:192201.

23. Smith JA, Jarman M, Osborn M. Doing interpretative phenomenological analysis. In: Murray M, Chamberlain K, editors. Qualitative health psychology: Theories and methods. London (UK): Sage Publications; 1999. p. 218-40.

24. Zigmond AS, Snaith RP. The Hospital Anxiety and Depression Scale. Acta Psychiatr Scand. 1983;67(6):361-70. [PMID:6880820] http://dx.doi.org/10.1111/j.1600-0447.1983.tb09716.x

25. Costantini M, Musso M, Viterbori P, Bonci F, Del Mastro L, Garrone O, Venturini M, Morasso G. Detecting psychological distress in cancer patients: Validity of the Italian version of the Hospital Anxiety and Depression Scale. Support Care Cancer. 1999;7(3):121-27. [PMID:10335929] http://dx.doi.org/10.1007/s005200050241

26. Rabin R, Oemar M, Oppe M. EQ-5D-3L user guide: Basic information on how to use the EQ-5D-3L instrument. Rotterdam (the Netherlands): EuroQol Group; 2011.

27. Zimet GD, Dahlem NW, Zimet SG, Farely GK. The multidimensional scale of perceived social support. J Pers Assess. 1988;52(1):30-41. http://dx.doi.org/10.1207/s15327752jpa5201_2

28. Prezza M, Principato MC. La rete sociale e il sostegno sociale In: Prezza M, Santinello M, editors. Conoscere la comunità. Bologna (Italy): Il Mulino; 2002. p. 193-233. Italian.

29. Endler NS, Parker JD. CISS Coping Inventory for Stressful Situations; Manual (Italian edition). Firenze (Italy): Giunti O. S. Organizzazzioni Speciali; 2009. Italian.

30. Eysenck HJ, Eysenck SB. Eysenck Personality Questionnaire-Revisited; Manual (Italian edition). Firenze (Italy): Giunti O. S. Organizzazioni Speciali; 2004. Italian.

31. Breakey JW. Body image: The lower limb amputee. JPO. 1997;9:58-66.

32. Gallagher P, Horgan O, Franchignoni F, Giordano A, MacLachlan M. Body image in people with lower-limb amputation: A Rasch analysis of the Amputee Body Image Scale. Am J Phys Med Rehabil. 2007;86(3):205-15. [PMID:17314705] http://dx.doi.org/10.1097/PHM.0b013e3180321439

33. Gallagher P, MacLachlan M. Development and psychometric evaluation of the Trinity Amputation and Prosthesis Experience Scales. Rehabil Psychol. 2000;45(2):130-54. http://dx.doi.org/10.1037/0090-5550.45.2.130

34. Desmond DM, MacLachlan M. Factor structure of the Trinity Amputation and Prosthesis Experience Scales (TAPES) with individuals with acquired upper limb amputations. Am J Phys Med Rehabil. 2005;84(7):506-13. [PMID:15973087] http://dx.doi.org/10.1097/01.phm.0000166885.16180.63 
35. Gallagher P, Franchignoni F, Giordano A, MacLachlan M. Trinity Amputation and Prosthesis Experience Scales: A psychometric assessment using classical test theory and rasch analysis. Am J Phys Med Rehabil. 2010;89(6):487-96. [PMID:20489393] http://dx.doi.org/10.1097/PHM.0b013e3181dd8cf1

36. Jackson CJ, Francis LJ. Interpreting the correlation between neuroticism and lie scale scores. Pers Individ Dif. 1999;26(1):59-63. http://dx.doi.org/10.1016/S0191-8869(98)00142-1

37. Desmond DM, MacLachlan M. Coping strategies as predictors of psychosocial adaptation in a sample of elderly veterans with acquired lower limb amputations. Soc Sci Med. 2006;62(1):208-16. [PMID:15990211] http://dx.doi.org/10.1016/j.socscimed.2005.05.011

38. Hanley MA, Jensen MP, Ehde DM, Hoffman AJ, Patterson DR, Robinson LR. Psychosocial predictors of long-term adjustment to lower-limb amputation and phantom limb pain. Disabil Rehabil. 2004;26(14-15):882-93. [PMID:15497917] http://dx.doi.org/10.1080/09638280410001708896

39. Williams RM, Ehde DM, Smith DG, Czerniecki JM, Hoffman AJ, Robinson LR. A two-year longitudinal study of social support following amputation. Disabil Rehabil. 2004;26(14-15):862-74. [PMID:15497915] http://dx.doi.org/10.1080/09638280410001708878

40. Unwin J, Kacperek L, Clarke C. A prospective study of positive adjustment to lower limb amputation. Clin Rehabil. 2009;23(11):1044-50. [PMID:19717504] http://dx.doi.org/10.1177/0269215509339001

41. Murray CD. Being like everybody else: The personal meanings of being a prosthesis user. Disabil Rehabil. 2009; 31(7):573-81. [PMID:19034778] http://dx.doi.org/10.1080/09638280802240290
42. Murray CD. The social meanings of prosthesis use. J Health Psychol. 2005;10(3):425-41. [PMID:15857872] http://dx.doi.org/10.1177/1359105305051431

43. Murray CD. An interpretative phenomenological analysis of the embodiment of artificial limbs. Disabil Rehabil. 2004;26(16):963-73. [PMID:15371044] http://dx.doi.org/10.1080/09638280410001696764

44. Bouffard J, Vincent C, Boulianne E, Lajoie S, Mercier C. Interactions between the phantom limb sensations, prosthesis use, and rehabilitation as seen by amputees and health professionals. JPO. 2012;24(1):25-33.

45. Nimhurchadha S, Gallagher P, Maclachlan M, Wegener ST. Identifying successful outcomes and important factors to consider in upper limb amputation rehabilitation: An international web-based Delphi survey. Disabil Rehabil. 2013;35(20):1726-33. [PMID:23350754] http://dx.doi.org/10.3109/09638288.2012.751138

Submitted for publication November 14, 2014. Accepted in revised form March 31, 2015.

This article and any supplementary material should be cited as follows:

Luchetti M, Cutti AG, Verni G, Sacchetti R, Rossi N. Impact of Michelangelo prosthetic hand: Findings from a crossover longitudinal study. J Rehabil Res Dev. 2015; 52(5):605-18.

http://dx.doi.org/10.1682/JRRD.2014.11.0283

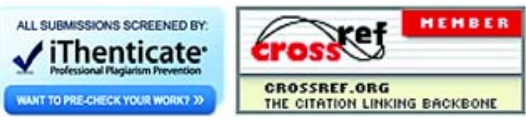

